\title{
Topology of Human Environment: Realistic and Futurological Evolution Modeling Based on the Transdisciplinary Methodology
}

\author{
Evgeny Kamensky ${ }^{1,2}$ \\ ${ }^{1}$ Belgorod State National Research University (NRU “BelSU”), Belgorod, Russian Federation \\ ${ }^{2}$ Southwest State University (SWSU), Kursk, Russian Federation \\ Correspondence: Evgeny Kamensky, Department of Philosophy and Sociology, Faculty of Economics and \\ Management, Southwest State University (SWSU), 94, 50 Let Oktyabrya St., 305040, Kursk, Russian Federation. \\ Tel: 7-471-222-2422. E-mail: kamensky80@mail.ru
}

Received: July 2, 2015 Accepted: September 10, $2015 \quad$ Online Published: September 21, 2015

doi:10.5539/res.v7n12p34 URL: http://dx.doi.org/10.5539/res.v7n12p34

\begin{abstract}
The article represents an attempt of creating and testing an interdisciplinary methodology of forming a topological concept of human environment as a complex system. Topology as a methodological matrix contains a potential of illustration and analysis of evolutionary changes of system objects in the social and humanitarian knowledge which is not fully realized. Macro-models developed on its basis give an insight into the regularities of the complex system dynamics with regard to its most significant, fundamental parametric properties.

The models of the evolution of human environment presented in the paper are focused on the issue of mankind technical and technological progress and the concomitant changes.

The most significant finding resulting from the study is the thesis concerning the necessity of forming a network structure as the most appropriate scenario for the future of the evolution the hierarchical form of human environment.
\end{abstract}

Keywords: topology, human environment, transdisciplinary methodology, realistic and futurological evolution

\section{Introduction}

Human environment, in our opinion, can be described from the standpoint of its topology, making it possible to identify more or less clearly the reference forms of the "environment" for human existence.

Therefore, the topology of human environment is a methodology for defining and describing the forms of the space of his activities, his human representation, but not just the species existence. In this case the space is understood within clear or fuzzy boundaries and meanings; it is constructed categorially according to the boundaries of the subject of scientific focus. To start such scientific research it is necessary to have a synthetic interdisciplinary construct of the topology content, and such its basic elements as topos and locus. The first problem which is immediately identified in this case lies in different understandings of the space of human life and activities; it is associated with its complexity reflected in the sociality, subjectness (of the activity), existential content, but not only with biologically-specific presence in the environment. We are primarily interested in the methodology with regard to the construction of topological concepts without taking into account the subject matter of their application. It is the methodology of scientific theorizing that should form the basis of the universalist model with just minor specific adjustments applicable to this or that problem.

Based on this methodology, we can consider the space of human environment in terms of system, structure, hierarchy, multidimensionality and their time-to-time variability, representing all these schematically in the most general topological models. The main thing here is an illustration of sustainable forms of the organization of the multidimensional space of human environment, including physical, biological, social, cultural and other characteristics, which are described by branches of science which are distant enough from each other. In this case, when speaking about a person, we mean all his subject-activity complexity and also the scope of the ontology in the natural world and the world objectified by him. Geometrically the forms represent the figures as the abstractions illustrating their specific properties. H. Poincaré wrote that figures first of all make up for the infirmity of our intellect by calling on the aid of our senses; the proportions may be grossly altered, but the relative positions of the different parts must not be upset. Therefore, the use of figures is, above all, then, for the 
purpose of making known certain relations between the objects that we study (Пуанкаре, 1972, p. 458). We can read the analysis of Papers on Topology written by J. Stillwell (Papers on Topology, 2009).

\section{Research Methodology}

Claiming to the creation of an interdisciplinary topological model of human environment, we think it is necessary to find out how the topological concept is reflected in the socio-humanitarian knowledge which today tends to use natural science and other similar preliminary studies that were non-typical to it earlier. Т.И. Макогон (2012, p. 167) notes: "Updated introduction of the concepts of space, field, spatial imagination, topology to the socio-philosophical discourse makes it possible to consider spatial, social and historical as evenly equivalent prospects".

For example, the tradition of using the concept of topos for the analysis of sustained stable forms of specifically understood space (language, text, literary work) was formed in Philology and Literary studies. E.R. Curcius (1997) was the most famous scientist, who introduced into scientific use in this area the concept of topos; the scientist defines them as stable forms of thought and its expression that capture phrases, expressions, formula, quotes, etc. Bachem (1955), Bornscheuer (1976), Grübel (1989), Lausberg (1973) and Schmidt-Biggeman (1983) continued the work in this area.

Криклевец (2014) notes: “[...] topos appears in the work both as a component of chronotope and as a kind of artistic image (universal image); it has not only real, presentive or concrete emotional aspect, but also abstract, conceptual and implied. The structure of topos in presentive aspect is an extensive network of spatial images (loci), joined by different semantic links and relationships".

Лотман (1970) also thinks that topos always corresponds to a particular object.

One of the scientists, who integrated topological categories into Social science, is Bourdieu (1974, 1982, 1985, 1987). Current researches in Social topology are also often based on the theories of Levin (1963).

Рябов (2007, p. 59) says that: "Social topology is, firstly, the study of invariant properties in the changing social space of multidimensional statistical distribution of the active properties of individual and collective agents. Secondly, it is a structure in which these properties appear in their integrity".

According to Шматко (2001, p. 16): "Each topos is associated with a kind of local social order. The concept of 'Social Topology' emphasizes the fact that not just 'social distance', a set of values of active properties distribution but inner form and qualitative specificity peculiar to the space-time structure of the ensembles of social phenomena, i.e. 'order', change from one topos to another".

It can also be seen that the understanding of topos is very close to the concept of a paradigm according to Kuhn (1970). In this case we observe the formation of certain forms (paradigms) in a certain social environment, as well as in the very field of scientific activity that makes it possible to talk both about the topological formations of this space, and its localization, and the existing relationships both between the topoi (forms) and inside them.

We consider that in this case synergistic foundations are the most successful methodological basis of scientific theorizing, since, despite their understanding in a rather broad sense up to the convergence of scientific and non-scientific knowledge, Synergetics has the most comprehensive tools, allowing getting out beyond the limitations of the branch subject matter and the methodology, taking into account common (not different) viewpoints on the problem. With regard to the subject of our study, we can appeal to the views expressed in scientific literature (see e.g., Каменский, Шаповалова, Боев, 2014а; Каменский, Боев, 2014b). For example, Григоровский $(2013$, p. 86) says that unlike most of new sciences that appeared, as a rule, at the intersection of disciplines which existed earlier and can be characterized by the penetration of methods of one science into the subject matter of another science, the picture of the knowledge unity of the environment of our existence arises relying not on the boundary points of different branches of science, but on their interior points.

In any case, it is obvious that in Social and Humanities Sciences, Topology studies the sustainable forms of a particular type of space or matter, the problems of their correlation and transformation in the structural and spatial, chronological and functional meaning; it is the core of its subject, regardless of the ontology of space and branch tools of its scientific analysis and description. However, special attention should be paid to the processes of sustainable forms (topoi) transition from one into another, occurring in the matter (substance) filling the space of the universe between the topoi. The first thing to do is to establish which of the forms of matter in the space of universe serves as the environment and/or as the conductor of dynamic processes of topoi transformation. We suppose that in the problem of human environment which is under our study, society and culture, that is, socio-cultural environment is this kind of matter. We will make an attempt to prove this thesis in this paper. 


\section{Results}

To build explicit models, it is necessary to structure the space of the human environment; to do this it is more convenient to use the traditional belief for science; according to this scientific belief human environment is understood as a set of three sub-environmental elements: natural, anthropogenic and technogenic. We will refer to these elements as sub-environmental loci, because it is in this kind of subspace that real human life exists and activities are carried out. These sub-environmental loci imply certain content determined by their genesis and ontology; they are also traditionally called spheres-for example, technosphere, etc (Note 1).

To create the most precise methodological framework of our study we differentiate the concepts of topos and locus. We consider the opinion of A.А. Булгакова to be the most appropriate from this point of view. She says that (Булгакова, 2007, p. 89): “[...] the relationships of the concepts of topos and locus are strictly hierarchical; large spatial units are called topoi, while loci do not reflect an abstract space as a whole, they reflect the specific place in a space "continuum"'.

Clarifying and refining the abovementioned opinion we consider a sustainable form of the organization of the space of human environment as the topos of human environment; and ontologically stable (i.e. relatively uniform in genesis and content) groups of the conditions of space (sphere) are considered as loci. That is the concepts of the space and sphere of human environment will be reflected in the constructs built on the basis of the identification of topoi and the representation of their sub-environmental structure (loci). The principle of hierarchical subalternity specified by А. А. Булгакова is also preserved in this model, since topos, being an integral system, acts, with regard to the loci forming it and their relationships, as an irreducible integrated whole to loci mechanical sum total.

Also, to achieve our objectives in support of the relevance of the topological human environment modeling as a methodological tool, we can rely on Kant's (2010, pp. 479-480) statement that: "The individual figure drawn upon paper is empirical; but it serves, notwithstanding, to indicate the conception, even in its universality, because in this empirical intuition we keep our eye merely on the act of the construction of the conception, and pay no attention to the various modes of determining it, for example, its size, the length of its sides, the size of its angles, these not in the least affecting the essential character of the conception".

This viewpoint is valuable precisely in relation to understanding of a form not in its empirical (geometric) representation, but in its ontologically meaningful description implying the necessity of establishing its essential properties (parametric: systemic, structural and other similar ones) that do not change depending on the scale and other aspects of depicting the topology of a space in the explicit models. This kind of observation allows us not to be related to a rigorous mathematical apparatus of topology in the socio-humanitarian knowledge, the use of which is often rather difficult for one reason or another. The important thing here is that a figure synthesis of imagination is a spatial synthesis, i.e. the formation of qualia (contemplation) with the help of a priori form of space. Accordingly, its result is a kind of (painted) "figure" (see e.g., Катречко, 2011).

Despite the fact that in some cases it is impossible to make consistent completely in their scientific definitions the approaches and concepts we use, the basic methodological principles in their subject creation and use can be synthesized and tested. Here we would like to explain our vision of the situation in detail. First of all, the synergistic principle of the impossibility of complete reduction explaining irreducibility of the complexity of hierarchical levels of the system to each other can be relevant to the problem of developing an adequate synthetic methodological model. However, these levels interact, having enough adherent points and information exchange channels, i.e. they are dissipative (see e.g., Prigogine and Nicolis, 1977).

For this reason they constitute integrity. The same can be said about a scientific theory, for example: it has a certain set of not only philosophical and field paradigms, but also of sub-theories and explanatory models; but, nevertheless, it forms certain worldviews that exist both in the chronotope of the development of human thought and in its current state and it also forms the tools for their studying. This is the topology of knowledge (in a broad sense of the word). A particular example of it is given in the description made by Kuhn (1970). Therefore, we understand any scientific theory as a reduced description of any object; it gives us only an alternative picture because it uses specific for it, but to be more precise for its author(s), expression language when similar or the same semantic content can be expressed in different concepts, and vice versa, common concepts can have different meanings. A typical example of this is, for instance, the use of the concept "culture". The invariant character of the very phenomenon of culture is so rich that it is most likely impossible to give its complete unreduced definition. This is especially true for the synthesis of inter-branch knowledge, the main problem of which up to now is the formation of a communication meta-language.

It is also impossible to ignore the methodological imperatives of the subject of cognition and knowledge 
generation. For example, if we internally put an accent on a technogenic factor as the most important, then, in future all factor dynamics will be built according to it, but objective effects or consequences of the effects of other factor groups can be reduced. It is such principles that act as the lens through which the researcher studies the object and describes it. In this case, it is the synthetic orientation of synergy that allows in the shortest possible time and with minimal epistemological expenses overcoming these difficulties, makes it possible to integrate methodological imperatives of different sciences, paradigms, sub-theories, and, in some cases, of scientific intuition and non-scientific knowledge.

Of course, in such situation the purity of developed concepts, approaches and tools of any universalist methodology can be criticized by adherents of a particular branch of science. However, we will try to implement the task of building topological models of human environment on the universalist-synergetic foundation. Based on our understanding of the topos presented above, we can identify certain sustainable forms of the ontology of human environment, the typing of which is made according to the stable hierarchical configurations of sub-environment loci that structure a particular topos. This is represented schematically in Figure 1.

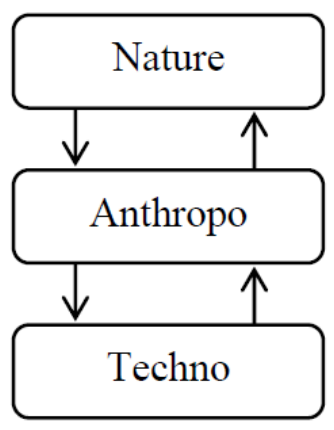

I

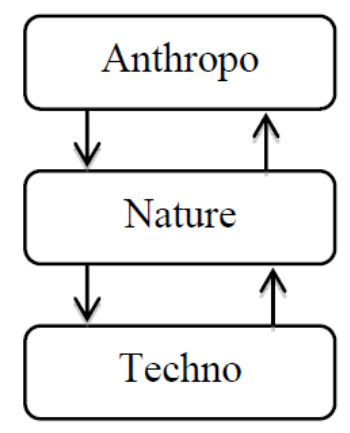

II

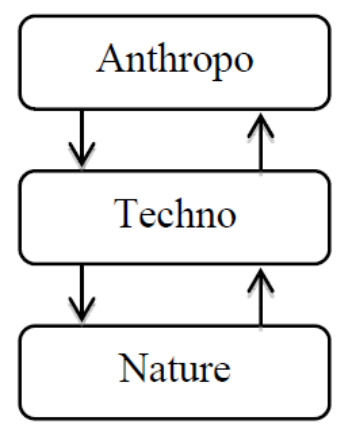

II

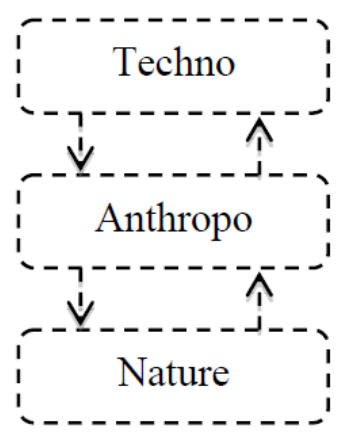

IV

Figure 1. Topological types (topoi) of human environment

In Figure 1 type IV is shown as a dashed line because it reflects only a trend of the development of the macro-system of human environment based on its extrapolation, but in reality it has not formed yet. It is an identifiable promising type of the development of human environment in its chronotope. It should be noted that in retrospect we could have introduced a zero topos to the model where anthropogenic locus did not exist, and the hierarchical structure of this topos was the simplest and would reflect human species isolation from the biological diversity of nature. We also could have identified as a zero topos a homogeneous in terms of its ontology natural environment presented unstructured in respect of the aspect of its understanding as human environment. But these topological types are meaningless for the goals of our work because they do not reflect the specifics of the environment in its contextual meaning for people. Of course, both of them, even containing the only natural locus, are not homogeneous if we take into account biological diversity and can be structured in a certain way. However, as we pointed out, this is beyond the scope of our study.

The analysis of the topology of human environment begins with type I for the reason that it reflects the subjective and activity status of a person, allowing us to identify the anthropogenic and anthropo-genetic character as the source of the formation of an independent sphere of human existence, presented by the corresponding locus. A similar reasoning is true for the technogenic locus.

We believe that the topological model presented in Figure 1 reflects the stable forms of hierarchical configurations of the structure of human environment. Sub-environmental loci, acting as the elements of this structure are in the identifiable relationship of hierarchy to each other, representing the type of structural sustainability. The criterion for building the hierarchies of the structure is the factor weight of the locus and the possibility of its reference to human existence. On the basis of these types of structures we identify the sustainable forms of the organization of environmental space, i.e. topoi. In this case, all the topological types (topoi) are in the relationships of chronological extension from one to another, i.e. in chronotope of human environment, illustrating the dynamics of the transformations of its topological organization in time (Figure 2). 


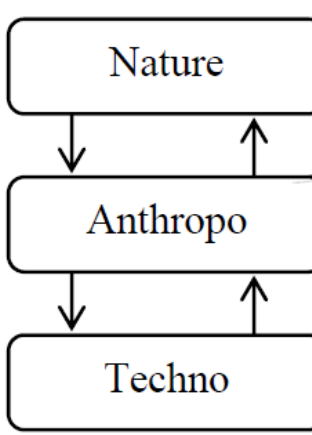

I

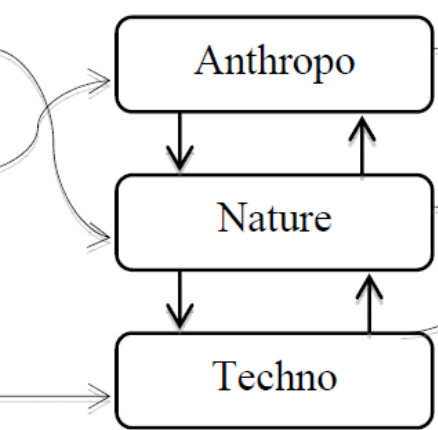

II

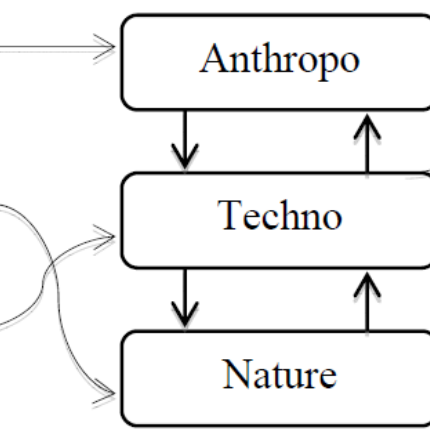

II

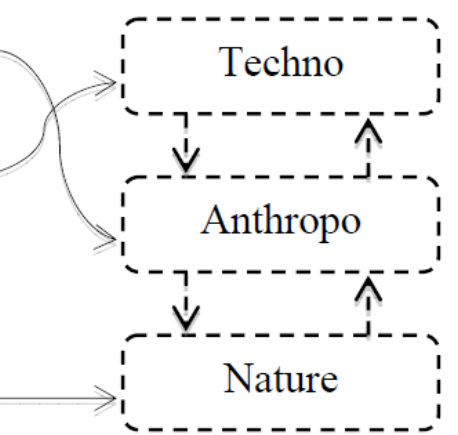

IV

Figure 2. The transformation of the topological structure of human environment in the process of its development (the dynamic of the changes of configurations of the structure of human environment topoi)

In this case, this transformation is due to the change in the loci factor configuration where the very configuration of loci changes when the weight of antroposociocultural factor increases. Type I of the topological structure (the content of the first topos) illustrates loci factor value in the process of homeostasis of the environmental space by means of the hierarchy of loci. These are homeostatic structures and they form the boundaries of the form-topos.

In other words, the types of hierarchies of parameters determine the type of homeostasis which is the content and the criterion for identifying the topoi (the forms). This statement is based on the fact that these types of homeostasis represent the "forms" of human environment and cannot be reduced to each other. According to the rules of topology these forms cannot be transformed into each other without losing their content, without "breaking" and "attaching", if we do not take into account the type of model building we use here. This allows us to consider them as ideal forms (topoi) of the space of human environment, or, that it is more appropriate, to consider them even more broadly - ideal forms of the environment as the general form (of the universe). In this case, it should be noted that the models we have developed and their characteristics are valid only in respect of two-dimensional space; 3-D models can be different and, what is the most important thing, their sustainable forms can change. However, we will return to this issue later.

To prove the model validity we can apply it, e.g., for the description of the types of civilizations given by B. C. Степин, as well as to the trends of civilization development (Figure 3).

\section{Trend}

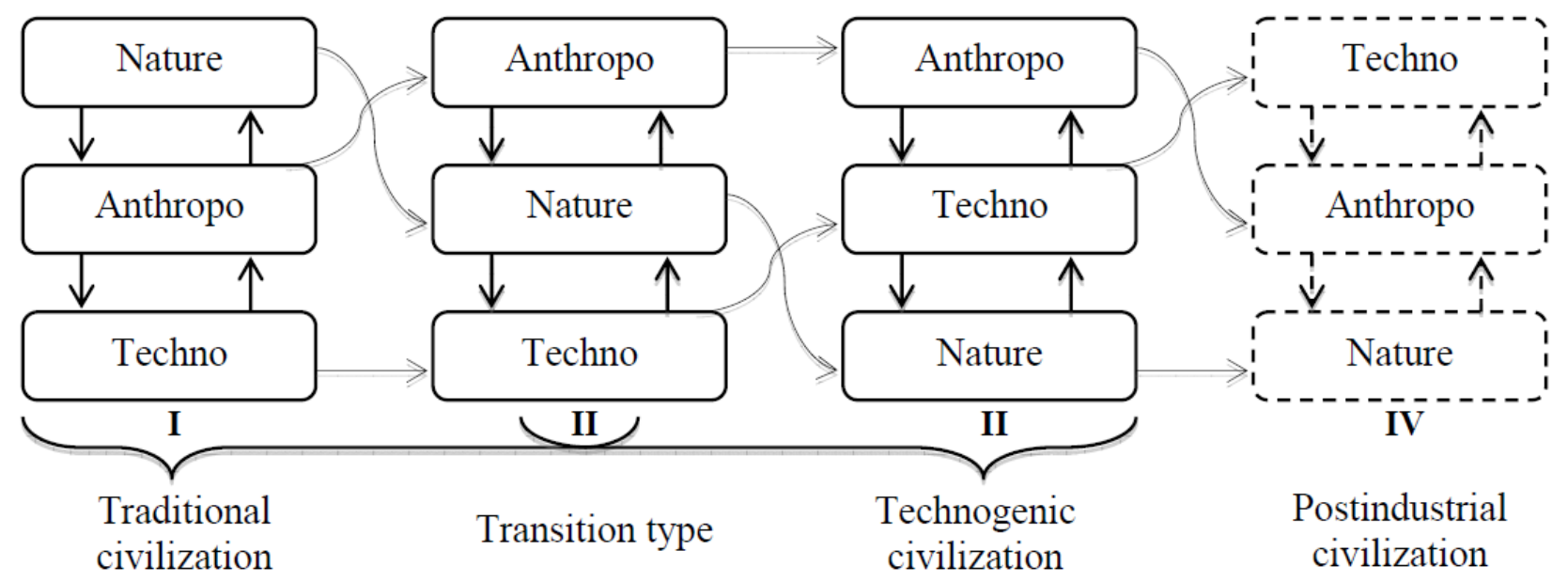

Figure 3. The ratio of topological and civilizational dynamics of human environment 
Figure 3 illustrates the processual dynamics of the transformation of the topology of human environment (in the context of the civilizational types of the society given by Степин (2011)). It is also very important here to take into account the change of the types of rationality described by В. С. Степин, as it allows us to understand the content of the processes which cause this transformation. This relation is due to the fact that Figure 3 shows not only the trend of the changes of the environmental space forms, but it also shows the dynamics of human worldview which largely determines the change in the factor structure of the topos by means of influencing the possibility of reference of anthropic and technogenic sub-environmental loci. The last statement will be explained later, when considering the problem of topoi transition from one type of the organization to another.

As you can see in the model given in Figure 3, topos II is represented as a transition topos in the civilizational development, and it can be partly identified in both civilization types-I and III.

It should be noted that the linear relationships, indicated in Figure 3 by straight arrowed lines, are typical only for two adjacent topoi with regard to a particular sub-environmental locus. Thus, topoi I and III, as well as topoi II and IV cannot be reduced to each other in any hierarchical configurations. This observation suggests the correspondence of such dynamics with wave-like synergistic development. That is, partial reducibility of adjacent topoi and irreducibility of next/previous ones, separated from each other by more than one cycle, illustrates the evolutionary type of development of the topology of human environment, but with fairly intensive changes. This kind of evolution reflects not only the sustainable process of self-development and self-organization of the environment as a system, but also demonstrates the scale of the changes occurring in it. Figure 3 shows that the linear relationships reflect the levels of stability in the adjacent topoi, remaining after the passage of the next phase of the development of the environment as a system. This model illustrates the phenomenon that we call "horizontal hierarchy", considered as a dynamic of the transformation of the topology of the environment, which is reflected in the change of the status of the parameters in the hierarchical configuration of sub-environmental loci.

It should be also noted that there is an open-ended list of possible configurations of sub-environmental loci of human environment in this model, but taking into account that the subject-activity (conative) component is typical only for anthropogenic locus, and for extrapolation in technogenic locus, the variation of the hierarchy of types V and VI is not essential for our study (Figure 4).

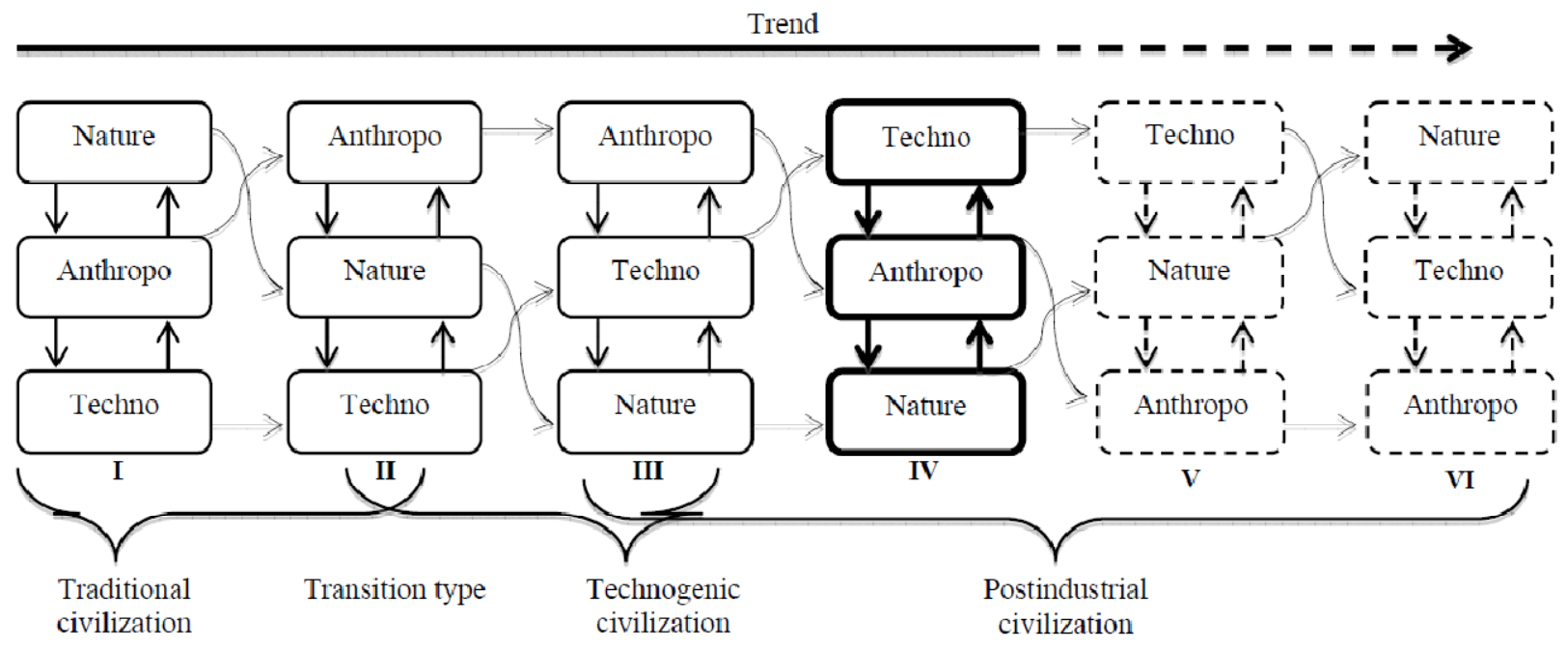

Figure 4. The extrapolation of the trends in the development of the topology of human environment (futurological aspect)

Even if it is granted that scenario $\mathrm{V}$ is probable, a person occurs at the bottom of the hierarchical structure in it; a person will no longer be an active subject in its modern understanding as "Homo sapiens", but just one of the species of this planet, who is not capable of active and conscious transformative activities, that is actually subjectivity. Accordingly, scenario V is apocalyptic for humanity in its antroposociocultural meaning. Scenario VI implies the subjectivity of nature but it is unimaginable in terms of understanding it as the subject of conative action in the modern scientific paradigm. Such a scenario cannot be formed even as extrapolation, since it implies the implementation of fantastic scenarios of demonstrating intelligence abilities by nature, e.g. by means 
of substituting a person by another intelligent species of biologicals.

In addition to the above said, this extrapolation is rather informative with respect to the illustration of the transition status of technogenic (industrial) type of civilization (given by В. С. Степин) to postindustrial (in the broad sense of the word), in case of the implementation of scenario IV, which is indicated by a thick line in Figure 4. Moreover, the intersection points of the trajectories of the loci in the process of transformation of the topoi structure, which reflects the development (changing) of human environment, are bifurcations, i.e. the moments of instability, phase transition, the change of the linear vector of the evolution of individual sub-environmental loci. In this case, the principle of circular causality is reflected in the change of the hierarchical statuses of sub-environmental loci which is associated with the changes in their parametric status. It is also seen in Figure 1-4 that in each transition from one topological type to another the linear relationship at one of the levels of their hierarchical structure remains. Moreover, these linear relationships can be seen only in respect of certain sub-environmental loci acting either as order parameters of the system of the initial and subsequent in the chronotope types of topos or as control parameters. At the level of the control parameters such effect is not observed. Such consistent patterns necessitate to determine the causes and to describe the processes of this structural change.

Now we think it is necessary to clarify certain methodological aspects in the construction of these configurations. First of all, understanding the factor value (the weight) of the locus as the criterion for determining its hierarchical status we focus on the resulting from this its parametric values. In this respect, we consider a synergistic approach to the problem of complex systems, their structure and development as the most applicable; we borrow the concepts of order parameters, the principle of dependence and circular causality from it (see e.g., Haken, 2012).

In the above models, taking into account the localization of sub-environmental loci of each topos, at one of the three levels of the hierarchy, the highest vertical locus has a maximum factor weight and acts as the order parameter in relation to the lower levels; the middle level illustrates the localization of the control parameters; the lowest level is a controlled one. Of course, such representation reduces the whole complexity of structural processes taking place in the system. But we deliberately use it for understanding the fundamental aspects of the problem under study.

In any case, the nature of the evolution of the topology of human environment, based on the change of parametric configuration of sub-environmental loci of the topoi shown in Figure 1-4, has a wave-like character. It is represented graphically in Figure 5; the ontologically identical loci of different topoi are marked identically. In this case, we restrict ourselves to the models shown in Figure 1-3, because they reflect retrospectively actual and prospectively the most likely course of the evolution of human environment, while topoi V and VI in Figure 4 are just futurological constructions.

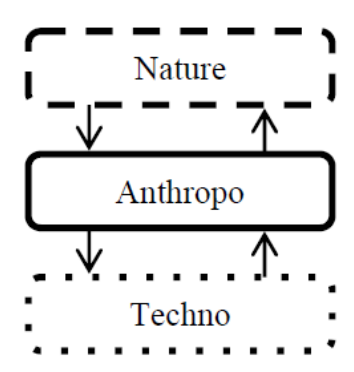

I

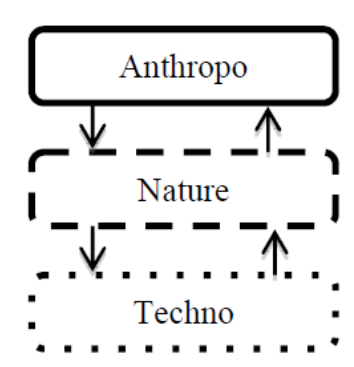

II

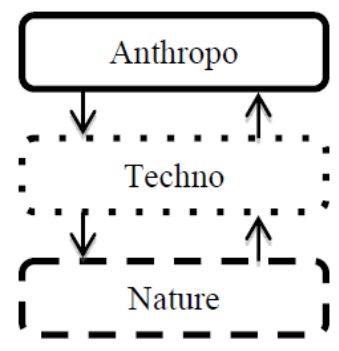

II

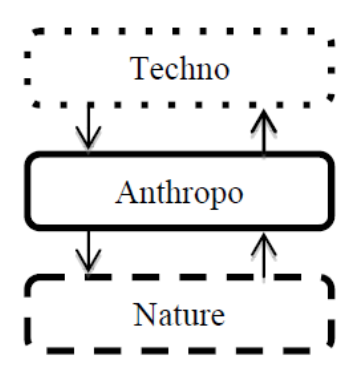

IV

Figure 5. Marking of the structural changes of the configuration of sub-environmental loci of human environment in the process of transformation of its topological types

Even more clearly than in Figure 5 this process can be represented in a different way. See Figure 6. 


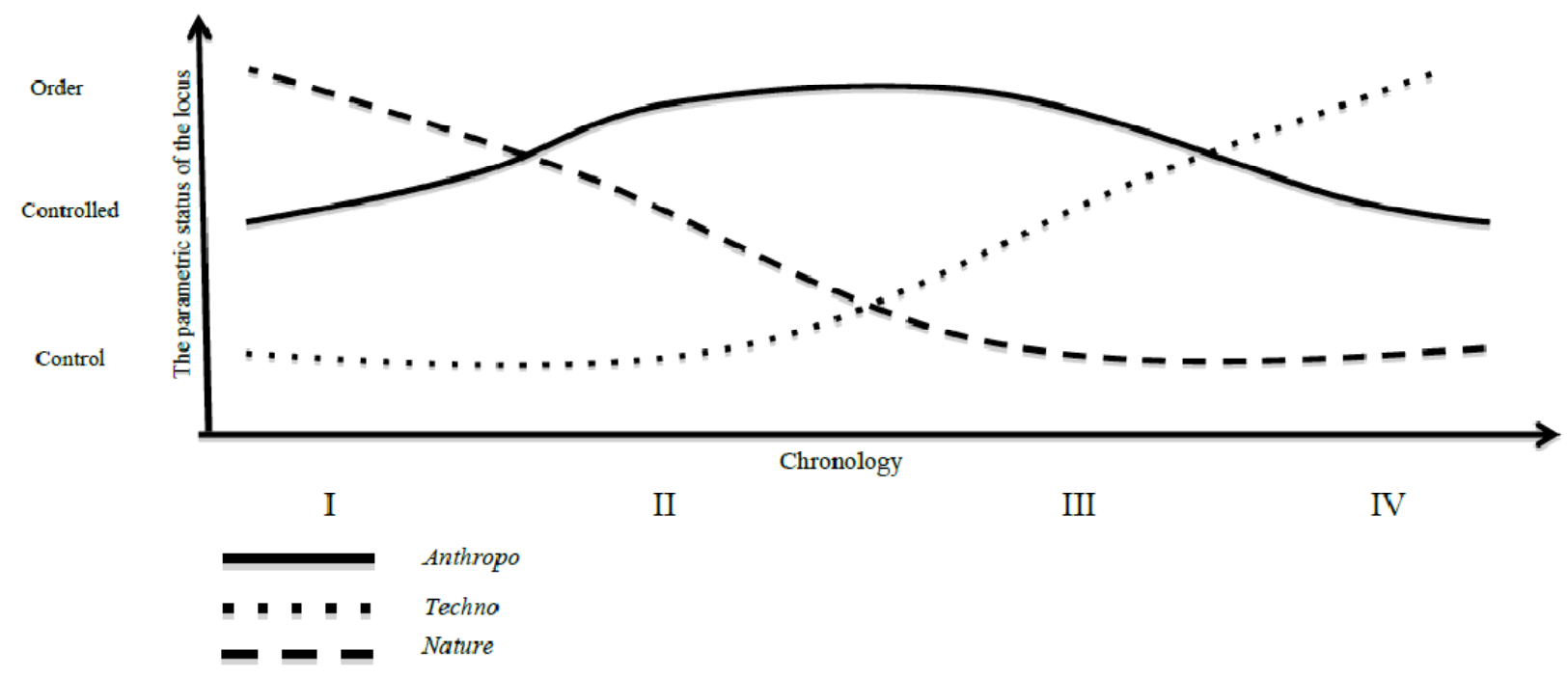

Figure 6. The wave-like character of the change of the parametric configuration of sub-environmental loci of human environment in the process of its topological development

Figure 6 shows the wave-like character of the evolutionary processes of the development of human environment: the dynamics of the fluctuations of the hierarchical status of anthropogenic locus in the topological structure is smaller in length and amplitude compared with the change of technogenic and natural spheres.

It is important to note that the significance of socio-cultural aspect of the processes that take place is probably illustrated here because culture (its changes, state, and etc.) can be included in the presented models as the filling, the substance, the social matter of the space between the topoi, in which it is actually necessary to look for the reasons of dynamic transformation of the sub-environmental (locus) content of the topoi in their transition from one relatively stable hierarchical configuration (homeostasis) to another. We think so because it is in the cultural space where the processes of the deconstruction and assembly of homeostatic forms of the structure of human environment are formed and implemented; these processes are associated primarily with human transformative activity and intellectual development, as well as with renovation of worldview imperatives of social life. Moreover, human activities are always goal-oriented; a person is a subject and the focus of his activities can be observed regardless of its main and indirect results and outcomes.

Figure 6 also shows that the trends in the evolution of the parametric configuration of the topological types in relation to technogenic and nature loci are reciprocally symmetrical, i.e. mirror each other; at the same time in wave-like representation the trend of the evolution of the anthropic locus has smaller fluctuations and length and does not fall below the middle level. This means that the anthropic locus does not degrade in the structure hierarchy lower than the factor value of the control parameters; currently, it is in the status of the order parameter with further downward trend back to the control status; in the realistic model it does not reach to the level of the controlled parameter.

In the case of the realization of futurological extrapolation scenarios of Figure 4 the waves of the changes of parametric status of the anthropic and technogenic loci will illustrate symmetrical inversely proportional to each other trend. In its turn, the wave of the changes of the parametric status of the nature locus has its own peculiar trend similarly to the specific character of the processes corresponding to the model shown in Figure 6 in relation to the anthropic locus.

In Figure 7 we can see that the symmetry of the three processes is observed from the point located on the chronological line in the area of the transformation of topological type III, which takes place nowadays, to type IV, built on the basis of extrapolation using modern futurological scenarios of the development of technosphere (see Technological Trajectories and the Human Environment 1997). In our opinion this point through which it is possible to draw the axis of symmetry can be called the moment of "anthropological turn" (see e.g., Konev 2014; Boev and Kamensky 2015), no matter how it is understood in the scientific community and in the context of modern human thought in general, whether it is a technological singularity or anything else (see e.g., Kurzweil 2005). Consequently, we can assume that the maintenance of the wave of evolution at the level not lower than 
the medium parameter value, still allows a person to exist as Homo sapiens.

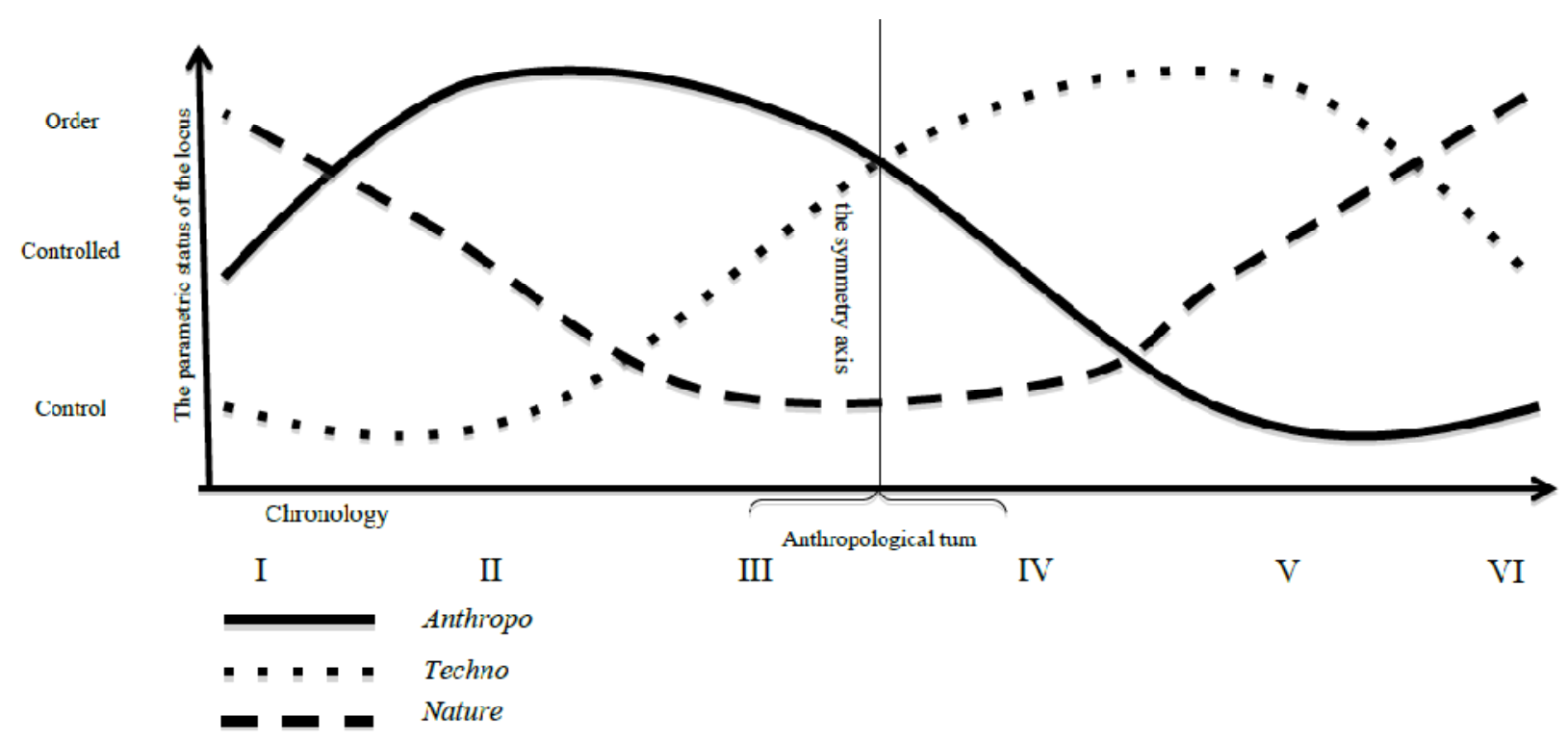

Figure 7. Futurological forecast of the wave-like dynamics of the topological evolution of human environment

Figure 7 shows that the topology of human environment is symmetric only in terms of ontology, because the integrated whole of sub-environmental loci as ontologically significant elements of its structure remains. The factor structure that characterizes the parametric values of the loci in the hierarchy of the structure of human environment and their changes is different. When analyzing the dynamics of the individual structural elements of the system the true symmetry can be observed only for nature locus; the two remaining loci illustrate the symmetrical pattern only in total, where the vector of the dynamics of each one individually, crossing the axis of symmetry, i.e., is passing through the point of "anthropological turn" enters the new parametric levels of the structure hierarchy, acting as a plane reflection of its "counterpart". In this case, there is an inversely proportional correlation between the dynamics of the change in the parametric status of anthropic and technogenic loci where the space surrounding the point of "anthropological turn" is an area of their approaching and, as a result of these trends, their intersection at this point. Due to these processes, according to the displayed in Figure 7 dynamics of the evolution of the nature locus, the proportional to them reduction of its factor weight can be observed; the only difference lies in the fact that to the left of the axis of symmetry there is a correlation with the increase of the parametric value of the anthropic locus, and to the right of it there is a correlation with the change of the factor weight of technogenic locus.

It is possible to overcome this scenario by specially organizing a network model of the configuration of human environment, which implies a rapid change of hierarchical status when planning missions and solving problems of human development, where human survival as a species is the most important thing. The built network model takes into account all the presented realistic hierarchical structure types, based on the principle of horizontal hierarchy which makes it possible to organize time hierarchical structures on the basis of different parametric configurations of three basic sub-environmental loci, which reflect the dynamic states of the network structure with respect to the center of the application of factor impact of the loci.

Thus, the dynamic state of the horizontal hierarchy can be considered as the ontological characteristic of the network structure of the human environment topos, reflecting the specific type of its homeostasis, where the static vertical hierarchical loci configurations will be a particular case of its functioning, resulting from the fact that the system "passes through a certain tunnel" of a goal. In this case, it is possible to speak of a universal ontological and factor structure of the topos of human environment, because there are no questions concerning the reductions of various evolutionary topological types to each other in their time structure for the moment of formation of the network form of topology left. But in the chronotope of the development of human environment, taking into consideration the predominance of non-linear processes in it, the impossibility of their reflexity and 
linear retrospection is obvious; this can be proved, for example, by the practice of the human transformation of nature. In case of the network form of the organization of the structure as a special type of homeostasis, based on the dynamic character of parametric configuration of its loci, the strict condition of its ontology is the presence of anthropic element in its subject-activity meaning in it. Otherwise, this kind of talks do not have any epistemological meaning, since the scenarios of the existence of the topological picture of human environment are reduced in terms of anthropology to scenarios " 0 ", "V" or "VI" of the futurological models presented above. Alternatively, the content of the modeling of such scenarios is neutralized by the fact of a "posthuman" genesis as a new irreducible to Homo sapiens form of entity, the probability of which though increases in proportion to the level and scope of scientific and technological progress, but is still too small to be taken into account in our reasoning.

The possibility of describing such effects occurs, if we place the model of the evolution of the topology of human environment in the horizontal plane of the three-dimensional space (Figure 8). In this case, different dynamic states of the topos of human environment, while maintaining the overall form can be seen in the network structure; this illustrates the phenomenon of horizontal hierarchy. Convergent-integral character of the network structure is most clearly illustrated by the character of the relationships of its constituent loci where there is their direct interaction; in the macro-statically stable vertical hierarchical structures, regardless of their topological type, the relationships of the order parameters and controlled parameters are mediated by the control parameter without any exceptions, and without any relation to the quantitative characteristics of the composition of any level in the hierarchy of parameters. Hence, the network form is based on a completely different principle of the organization of the factor-parametric structure of its ontology, and this principle is operative dynamics of its parametric configuration.

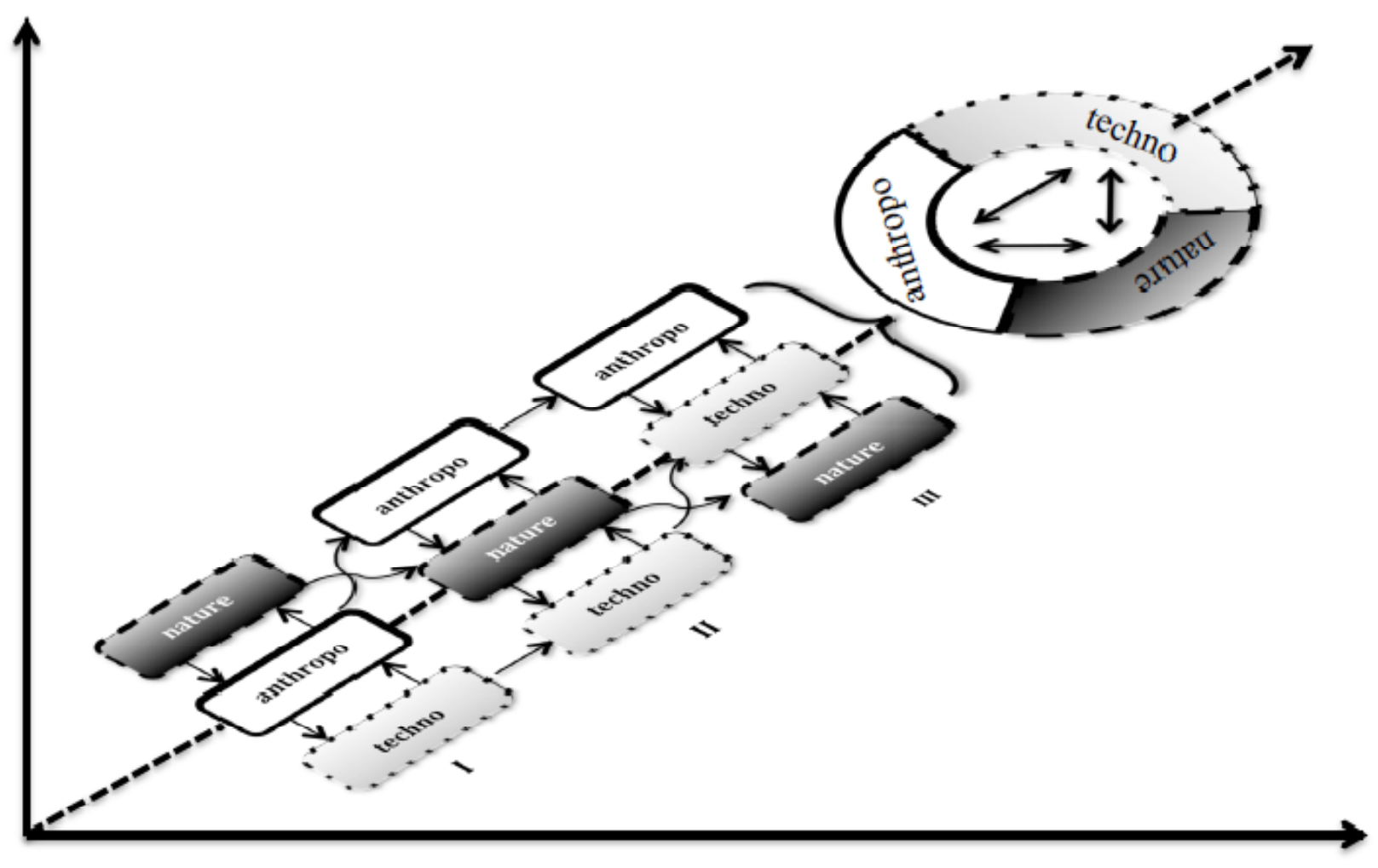

Figure 8. Scenario of the formation of the network structure of human environment in the process of its topological evolution

We believe it is possible to say that on the basis of the build models the ontological homomorphism of the topology of human environment can be illustrated. However, when comparing the structural configuration (factorial structure) of the topological types it is necessary to explain the features of this homomorphism, which we understand not in the mathematical interpretation, but in the interpretation adapted to the socio-humanitarian knowledge. That is a homomorphism will mean the uniformity of the forms of certain objects in terms of their 
content (structure, hierarchy, relationships, etc.). First of all, our position can be clarified by determining the types of homomorphism which can be observed in the evolution of the topology of human environment. The basic statements here are as follows:

1) Homomorphism of human environment in terms of ontology can be described by any of its type, because, in this case, retaining its basic sub-environmental loci, regardless of their parametrical configurations in the ontological structure is the main condition.

2) The factor structure of human environment cannot be described using all the types of homomorphism since the parametric configuration of sub-environmental loci is the main criterion of distinguishing one topological type from another, and the dynamics of its change defines the topological evolution of the environment and gives meaning to its analysis. In this case, such type of homomorphism as isomorphism, implying a linear bijection of the structure of the adjacent topological types is impossible. It is most likely a kind of epimorphism, where the adjacent topological types are reduced to each other in respect of the loci illustrating a linear relationship in the dynamics of their structure changing, with regard of the other loci the parametric changes can be observed. In this case, it is important that this or that type of factor structure can be understood as an independent form of topological organization, while the ontological structure of human environment is endomorphic, i.e. morphic to itself.

Such phenomena can be explained by the fact that a complete reduction of the topological types to each other is impossible; in the topological types the analog of the hierarchy of the very evolutionary process is the evolutionary chronological development of the structural changes of the topos of human environment, that is, its temporal and processual structure. We consider the process of changes presented in figures as an evolutionary development, i.e. a chronological hierarchical structure. This statement is based on our confidence in "human-caused" as any kind of human cognition and his transformative and any other subject activity, their reflexive character. In this case, conventionally, each subsequent topological type corresponds to the previous one in the temporal structure of the hierarchy of the evolution of human environment as higher level to lower level.

It is seen that in the horizontal plane of three-dimensional space (Figure 8) all the topological types are homomorphic; the difference lies only in individual (chronologically defined, static) configuration of sub-environmental loci of the structure. The unchangeable characteristic of all the topological types as the objects is the genesis of their ontology. It is ontology that allows us to state that topological types are isomorphic. We mean the fact that any of sub-environmental loci that can also be understood as a subspace or sphere (or a particular specific place in it) in human environment, is genetically determined by the evolution of the planet nature. In our opinion, the most suitable explanatory construct in this case is the so-called anthropic principle which was introduced by us in this study; according to this principle, putting it mildly, the whole evolution of the local universe leads to the appearance of an observer, "a human" as a specific form of physical organization of matter (in the broadest sense of the word), a tool for self-understanding and will (conative) transformation of the universe. A human is a reflection of the universe. In the same way Sociology identifies the concepts of "a person" and "society", speaking of a person as a reflected society in a human through his subjectivity and social identity, as well as typical character which correspond to the phenomenon of unity and differentiation. As it is seen there is a kind of agreement of the principles of understanding a person in both cases; there is the only difference - the scope of the mentioned examples, but, nevertheless, this allows us to see the universalist features in this kind of understanding of the problem under study.

\section{Conclusions}

The undertaken attempt to adapt the topological constructs for analyzing and describing the processes of sustainability and changes in human environment as a complex system made it possible to ascertain flexibility of synergetic methodology, a high degree of adaptability of its imperatives to solve specific problems based on the use of the universalist understanding of the categories of "system", "structure", "form", "topos", "locus" and the others, represented in this article. The heuristic value of the classical approaches and ideas of scientific and philosophical thinking, presented in the cited above works, the depth and complexity of their authors' contribution to the understanding of the world and human cognitive abilities are also illustrated.

Summarizing the above written, we come to the following conclusions.

The topological conceptual framework of the description of human environment is based on the identification and topologization of the parametric configuration of its sub-environmental loci, forming hierarchical structures which are stable in space and time, and which define the boundaries of the content of a particular type of the human environment form (topos). The topological models presented in the figures reflect the dynamics of the 
evolutionary process of human environment through the change in the parametric configuration of its ontology, where the changes in the structure and hierarchy of sub-environmental loci result from the change of their factor weight. As a consequence, the parametric status of the ontological factors, i.e. the very factor structure changes. Thus, the change in the ontological structure of human environment is determined by the change in its factor structure. Here we can speak both of the stability of the system in terms of its ontology which is consistently outlined in modern science by traditional for it nature, anthropogenic (social and cultural) and technogenic elements, and of the dynamism of its factor structure transforming the types of its hierarchy, resulting from the change of the factor weight of the sub-environmental loci and, as a consequence, their parametric status in the hierarchy of the environmental structure.

When realizing either realistic or futurological scenarios we can understand all topological types as an indivisible stage in the evolution of human environment from the homogeneous state to the complex one, through the development of sub-environmental loci of zero type "nature" to the built network type (Figure 8). However, the homomorphism of such a model can be recognized, only at the macro level because, getting involved into the particular processes occurring at least at the level of existence in any of the represented topoi types, we will make sure in the impossibility of the reduction of the macro-levels to the hierarchically lower levels, although the general ontological principles of their functioning are likely to persist. However, the "substrate" (socio-cultural, natural, and technologic spheres) in the context of which these processes occur varies considerably, making it necessary to differentiate the methodological imperatives of their studying, taking into account the contextual properties of these spaces and spheres, of the very objects, defining the specificity of their interactions.

Thus, the undertaken attempt to form a topological model of the description of human environment is an illustration of its understanding at the macro-level both in methodological and in space aspect. In the future, it allows us to structure the model according to particular research tasks; we hope this will give us an opportunity to study and describe the very mechanism of the represented evolutionary processes, which takes into account the features of the environment, the course of the processes development, their laws and regularities, as well as the possibility to verify the methodological constructs in scientific and philosophical knowledge. In other words, it is necessary to study the spaces in close connection with the contexts of human existence and the specific types of his subjective activity in spatial and contextual relationships.

\section{Acknowledgements}

The research is financed by Russian Science Foundation, project No 14-38-00047 "Forecasting effort and social risks management of anthropogenic human-caused systems development over time human environment transformation processes" through the activities of joint Scientific laboratory of transdisciplinary research of Belgorod State National Research University (Belgorod), Institute of Socio-Political Research RAS (Moscow), Southwest State University (Kursk).

\section{References}

Ausubel, J. H., \& Dale Langford, H. (Eds.). (1997). Technological Trajectories and the Human Environment (p. 224). Washington, DC: National Academy Press.

Bachem, R. (1955). Dichtung ais verborgene Teologie; ein dichtungstheoretischer Topos vom Barok bis zur Goethezeit und seine Vorbilder (p. 198). Bonn.

Bornscheuer, L. (1976). Topic. Zur Struktur der gesselschaftlicher Einbildungskraft (p. 232). Frankfurt am Main.

Bourdieu, P. (1974). Zur Soziologie der symbolischren Formen (p. 204). Frankfurt am Main: Suhrkamp.

Bourdieu, P. (1982). Die feinen Unterschiede (p. 391). Frankfurt am Main: Suhrkamp.

Bourdieu, P. (1985). Sozialer Raum und Klassen (p. 82). Frankfurt am Main: Suhrkamp.

Bourdieu, P. (1987). Sozialer Sinn (p. 186). Frankfurt am Main: Suhrkamp.

Булгакова, А. А. (2008). Топика в литературном процессе (р. 107). Гродно: ГрГУ им. Я. Купалы.

Curcius, E. R. (1997). Literatura europejska i tacińskie średniowiecze (p. 384). Tłum. ï oprac. A. Borówski. Krakow.

Степин, В. С. (2011). Цивилизация и культура (р. 408). Санкт-Петербург: СПбГУП.

Grübel R. (1989). Convention and innovation in literature (p. 284). Amsterdam; Philadelphia: J. Benjamins Pub. Co. 
Haken, H. (2012). Synergetics: An Introduction (p. 408). Berlin; Heidelberg; New York; Tokyo: Springer-Verlag.

Каменский, Е. Г., \& Боев, Е. И. (2014b). Техногенная человекомерная система: тезисы по футурологии антропотехнической гибридизации. Известия Юго-Западного государственного университета. Серия: Экономика. Социология. Менеджмент, 4, 142-149.

Каменский, Е. Г., Шаповалова, И. С., \& Боев, Е. И. (2014а). Человек, общество, техника: общие тезисы по методологии и онтологии проблемы. Известия Юго-Западного государственного университета. Серия: Экономика. Соииология. Менеджмент, 3, 109-116.

Kamensky, E. (2014). Instrumental Theoretical and Methodolodgical Construct of a Conception of the Human Environment. Pensee, 76(11), 9-21.

Kamensky, E., \& Boev, E. (2015). An Innovation Civilization in the Context of the Anthroposphere Crisis of the Technogenic Society. Asian Social Science, 11(4), 328-335.

Kant I. (2010). Critique of Pure Reason (p. 566). Philadelphia, PA: The Pennsylvania State University.

Катречко, С. Л. (2011). Моделирование рассуждений в математике: трансиендентальный подход (рр. 147-161). Модели рассуждений - 4: Аргументация и риторика.

Конев, В. А. (2014). Антропологический поворот / разворот культуры - новый вариант проекта модерна. Международный журнал исследований культуры, 2(15), 5-11.

Криклевец, Е. В. (2014). Художественныгй мир В. Астафьева и В. Козько: спеиифика пространственно-временной организаџии (р. 107). Витебск: ВГУ им. П.М. Машерова.

Kuhn, T. (1970). The Structure of Scientific Revolutions. Chicago: The University of Chicago Press.

Kurzweil, R. (2005). The Singularity Is Near. New York: Viking.

Lausberg H. (1973). Nandbuch der liretarischen Rhetoric (p. 302). Munchen.

Levin, K. (1963). Feldtheorie in den Sozialwissenschaften. Ausgewählte theoretische Schriften (p. 395). Bern und Stuttgart: Verlag Hans Huber, $395 \mathrm{~s}$.

Макогон Т. И. (2012). Возникновение топологического восприятия пространства в теориях социальных полей. Известия Томского политехнического университета, 321(6), 162-167.

Papers on Topology: Analysis Situs and Its Five Supplements. Henri Poincaré. (2009). A co-publication of the AMS and the London Mathematical Society. Retrieved January 16, 2015, from http://maths.ed.ac.uk/ aar/papers/poincare2009.pdf

Prigogine, I., \& Nicolis, G. (1977). Self-Organization in Non-Equilibrium Systems: From Dissipative Structures to Order Through Fluctuations. New York: J. Wiley \& Sons.

Рябов, М. А. (2007). Субъектность в структурах социальной топологии. Вестник Удмуртского университета, 3, 51-64.

Schmidt-Biggeman, W. (1983). Topica universalis. Eine Modellgeschichte humanistischer und barocher Wissenschaft (p. 318). Hamburg.

Григоровский, Б. К. (2013). Синергетические действия и представления. Вестник СамГУПС, 4(22), 86-96.

Лотман, Ю. М. (1970). Структура художественного текста (р. 384). Москва: Искусство.

Пуанкаре, А. (1972). Избранные труды в трех томах. Т. ІІ. Новые методы небесной механики. Топология. Теория чисел (р. 1001). Москва: Наука.

Шматко, Н. А. (2001). Плюрализация социального порядка и социальная топология. Социологические исследования, 9, 14-18.

Note.

Note 1. For detailed consideration of this point, see Kamensky, E. (2014). Instrumental Theoretical and Methodolodgical Construct of a Conception of the Human Environment'. Pensee, 76(11), 9-21. 


\section{Copyrights}

Copyright for this article is retained by the author(s), with first publication rights granted to the journal.

This is an open-access article distributed under the terms and conditions of the Creative Commons Attribution license (http://creativecommons.org/licenses/by/3.0/). 